Article

\title{
Optimization of Indole-3-Acetic Acid Concentration in a Nutrient Solution for Increasing Bioactive Compound Accumulation and Production of Agastache rugosa in a Plant Factory
}

\author{
Vu Phong Lam ${ }^{1,2, \dagger}$, Mun Haeng Lee ${ }^{3, \dagger}$ and Jong Seok Park ${ }^{1, *}$ \\ 1 Department of Horticultural Science, Chungnam National University, Daejeon 34134, Korea; \\ phonglamdhtaybac@gmail.com \\ 2 Department of Agronomy, Tay Bac University, Son La 360000, Vietnam \\ 3 Fruit Vegetable Research Institute Chungnam-do A.R.E.S, Buyeo 33119, Chungnam, Korea; \\ dogue24@gmail.com \\ * Correspondence: jongseok@cnu.ac.kr; Tel.: +82-42-821-5737 \\ $\dagger$ These authors contributed equally to the work.
}

Received: 23 June 2020; Accepted: 7 August 2020; Published: 9 August 2020

\begin{abstract}
This study aimed to determine the optimal indole-3-acetic acid (IAA) concentration in a nutrient solution to increase the bioactive compounds while enhancing the plant growth of $A$. rugosa grown hydroponically. Twenty-eight-day-old plants were transplanted in a plant factory for 32 days. The plants were subjected to various IAA concentrations $\left(10^{-11}, 10^{-9}, 10^{-7}\right.$, and $\left.10^{-5} \mathrm{M}\right)$ from 8 days after transplanting, and the control treatment (without IAA). Shoot and root fresh weights were effectively improved under $10^{-7}$ and $10^{-9}$ IAA treatments. Leaf gas exchange parameters were increased under $10^{-7}$ and $10^{-9}$ IAA treatments. Four of the IAA treatments, except $10^{-11}$ IAA treatment, significantly increased the rosmarinic acid (RA) concentration, as well as the tilianin concentration was significantly increased at all IAA treatments, compared with that of the control. Especially, the tilianin concentration of the $10^{-11}$ IAA treatment was significantly (1.8 times) higher than that of the control. The IAA treatments at $10^{-5}$ and $10^{-7}$ significantly raised the acacetin concentrations (1.6- and 1.7-times, respectively) compared to those of the control. These results suggested that $10^{-7}$ concentration of IAA in a nutrient solution was effective for enhancing plant growth and increasing bioactive compounds in A. rugosa, which offers an effective strategy for increasing phytochemical production in a plant factory.
\end{abstract}

Keywords: acacetin; growth parameter; phytochemical; rosmarinic acid; tilianin

\section{Introduction}

The requirement for medicinal plants on a global scale such as Agastache rugosa is increasing [1,2]. A. rugosa (Lamiaceae family) is a popular herbaceous plant, and its leaves have been largely used as food flavor in daily cuisines. All parts of this plant are used as traditional pharmaceuticals to treat different disorders in various civilizations' medical systems [3]. A. rugosa is rich in phytochemicals such as chlorogenic, ferulic, caffeic, and rosmarinic acid (RA), as well as flavone glycosides, sesquiterpenes, tilianin, diterpenes, acacetin, and triterpene [4-6]. Furthermore, the previous reports indicated that rosmarinic acid, tilianin, and acacetin are the main active compounds of $A$. rugosa [5,7]. They are famous for their pharmacological activities such as anti-allergic, antioxidant, anti-microbial, anti-tumor, anti-depression, anti-cancer, anti-viral, antioxidant activities, and anti-asthmatic [3,8-12]. The quality of these herb plants enables assessment of their concentrations of secondary metabolic compounds [13]. 
Food production with high quality and productivity can be achieved by growing in a plant factory, which is one way to satisfy very specific requirements for plant growth and secondary metabolite accumulation [14]. Various external factors such as the light, temperature, electrical conductivity, root temperature, and hormones affect the accumulation of bioactive compounds in A. rugosa [15-18]. Furthermore, plant hormones such as indole-3-butyric acid (IBA), 1-naphtha-leneacetic acid (NAA), indole-3-acetic acid (IAA), and phenylacetic acid (PAA) play an essential role not only in the growth but also in the accumulation of antioxidant enzymes and bioactive compounds in plants $[19,20]$. Plant hormones can change the activity of antioxidant enzymes and the antioxidant synthesis, and some of these enzymes are related to phytohormone synthesis [21]. For example, the activity of antioxidant enzymes was increased by auxin to adjust reactive oxygen species levels, which may be related to the activation of embryo/organogenesis [21]. The growth and amounts of bioactive contents in plants rely on the concentrations of hormones [22]. IAA is an important auxin that has a strong influence on the growth and development of Acutodesmus obliquus and IAA-enhanced cell proliferation and antioxidant properties in plants [23]. Rutin and protein contents of the white mulberry tree were increased by increasing the IAA concentration into the incubation medium [22]. The ajmalicine concentration in the shoot of Catharanthus roseus was increased under high IAA concentration $(11.42 \mu \mathrm{M})$ [24]. The highest monosaccharide content (73\%) in Chlorella vulgaris was obtained under $0.1 \mu \mathrm{M}$ IAA concentration compared with the control [20]. These results showed that it is possible to improve the nutritional quality in terms of phytochemicals in plants by controlling the IAA concentration levels. Thus, the application of IAA could be a beneficial tool for increasing the bioactive compounds in A. rugosa for fresh consumption or functional ingredients for nutraceutical food.

To date, several studies have examined the effects of IAA concentration on the accumulation of bioactive compounds in plants; however, most were performed in vitro cultivation [22,24]. No report has shown whether the IAA dissolved in nutrient solution stimulates bioactive compounds in A. rugosa grown under a deep flow technique system in a plant factory with artificial light. Therefore, this study aimed to evaluate the effects of IAA concentration levels in Hoagland's nutrient solution on the chlorophyll content, leaf gas exchange parameters, growth, and accumulation of bioactive compounds in A. rugosa grown in a closed plant factory and to try to determine the optimal IAA concentration treatment to raise the tilianin, $\mathrm{RA}$, and acacetin concentrations with advantageous effects on plant growth.

\section{Materials and Methods}

\subsection{Plant Materials and Seedling Conditions}

A. rugosa (Danong Seed Co., Ltd., Seoul, Korea) seeds were sown according to the method described in Lam et al. (2020) [18]. Germinated seeds were grown for 4 weeks in a closed plant factory with environmental control of air temperature at $22 / 18^{\circ} \mathrm{C}$ (light/dark), a relative humidity of $60-80 \%$, photoperiod period of $16 \mathrm{~h}$ per day, and photosynthetic photon flux density (PPFD) of $180 \pm 10 \mu \mathrm{mol} \cdot \mathrm{m}^{-2} \cdot \mathrm{s}^{-1}$ irradiated by fluorescent lamps (TL5 14W/865 Philips, Amsterdam, Netherlands) for 28 days. The seedlings were watered by the Hoagland solution from 15 days after sowing $[18,25]$. The $\mathrm{pH}$ and electrical conductivity (EC) values of the nutrient solution (NS) were controlled to around 6.0 and $1.1 \mathrm{dS} \cdot \mathrm{m}^{-1}$, respectively.

\subsection{Auxin Experiment and Growth Conditions}

At 28 days after sowing, eighteen $A$. rugosa young plants at the four leaves stage were transferred into a deep flow technique system $(1.0 \times 1.29 \times 0.11 \mathrm{~m} ; \mathrm{W} \times \mathrm{L} \times \mathrm{H})$ in a plant factory (Figure 1$)$ and subjected to PPFD of $200 \pm 10 \mu \mathrm{mol} \cdot \mathrm{m}^{-2} \cdot \mathrm{s}^{-1}$ with a photoperiod of $14 \mathrm{~h}$ for 32 days, using light-emitting diode lamps (TL5 14W/865 Philips, Amsterdam, Netherlands). The average air temperature and relative humidity of the plant factory were maintained at $22 \pm 3{ }^{\circ} \mathrm{C}$ and $70 \pm 10 \%$, respectively. Hoagland nutrient solution with the EC of $2.0 \mathrm{dS} . \mathrm{m}^{-1}$ and $\mathrm{pH}$ value around 6.0 was provided for all A. rugosa 
plants during the experiment period. Eight days after transplanting, plants were treated with four different concentrations of IAA $\left(10^{-11}, 10^{-9}, 10^{-7}\right.$, and $10^{-5} \mathrm{M} ; 0.00000000175,0.000000175,0.0000175$, $0.00175 \mathrm{~g} \cdot \mathrm{L}^{-1}$, respectively) while control plants were treated with similar volume without IAA concentration. Indole-3-acetic acid (IAA) stock solution was prepared according to the manufacturer's instructions (Gold Biotechnology, St. Louis, MO, USA). Briefly, $0.14 \mathrm{~g}$ of indole-3-acetic acid powder was dissolved in $1.5 \mathrm{~mL}$ of ethanol (EtOH) and diluted to $100 \mathrm{~mL}$ with deionized water. The nutrient solution reservoir had a volume of $80 \mathrm{~L}$. Both nutrient reservoir containing IAA and the grow trays were covered by the silver paper to protect IAA from degradation. This experiment was repeated twice with the same experimental unit (a hydroponic culture system) at the same location under the same environmental conditions.

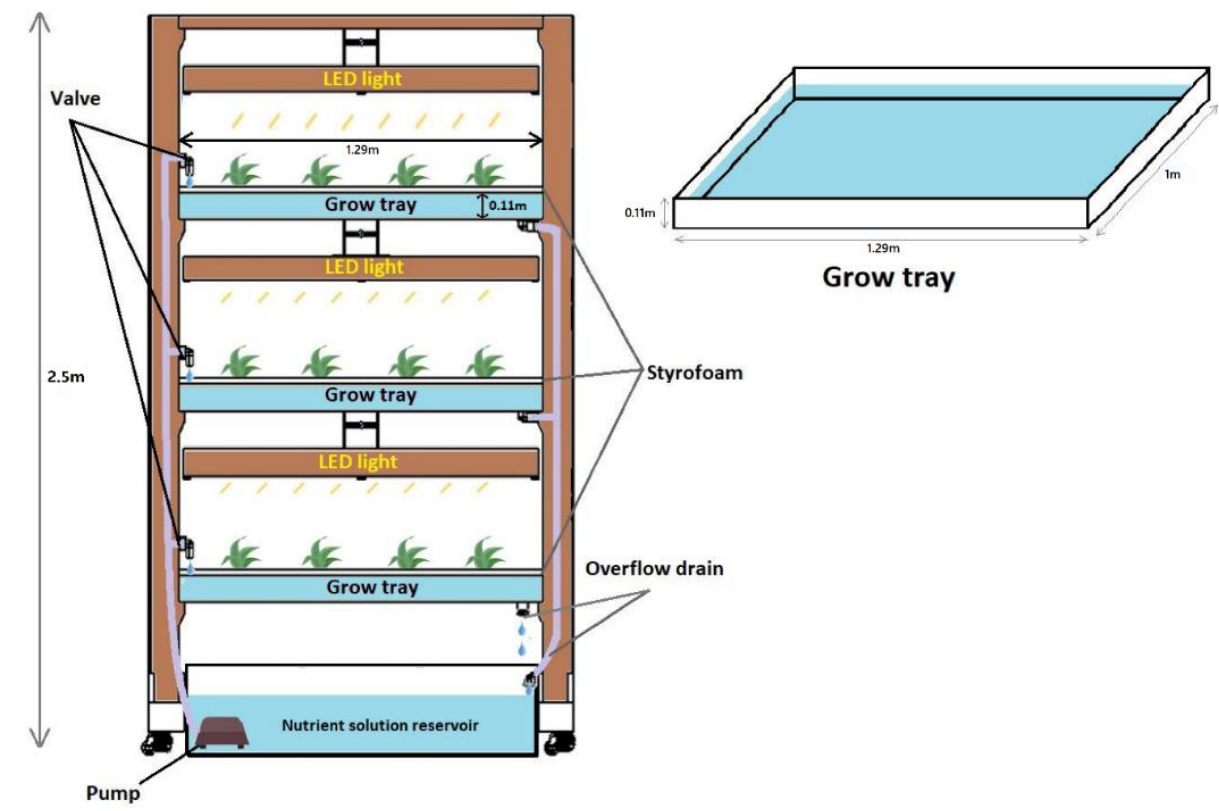

Figure 1. A deep flow technique (DFT) system in a plant factory. The plants were cultivated on a styrofoam board and placed on the surface of the nutrient solution with dissolved indole-3-acetic acidand the control treatment (without dissolved IAA).

\subsection{Measurement of Growth Parameters}

All plants for the IAA experiment were harvested at 32 days after transplanting and 8 plants were used for measuring all plant growth parameters per each replication. The number of leaves, which are longer than $1 \mathrm{~cm}$ and broader than $1 \mathrm{~cm}$ were counted. Leaf area was measured using a Li-3100 leaf area meter (LiCor, Lincoln, NE, USA). A tape measure was used to record leaf width and length, and stem and root lengths. The fresh weights of shoots and roots were separately determined using a micro weighing scale (CAS MW-II, CAS Co., Ltd., East Rutherford, NJ, USA). The fresh shoots and roots were dried at $70{ }^{\circ} \mathrm{C}$ in a drying oven (HB-502M, Hanback Sci, Suwon, Korea) for seven days to determine shoot and root dry weights.

\subsection{Chlorophyll Fluorescence (Fv/Fm) and Relative Chlorophyll Values}

The ratio of variable to maximum fluorescence $\left(\mathrm{F}_{\mathrm{v}} / \mathrm{F}_{\mathrm{m}}\right)$ and relative chlorophyll values were measured by a portable fluorometer (Fluorpen Pen FP 100, Photon System Instruments Ltd., Drasov, Czech Republic) and a portable chlorophyll meter (502, Minolta Camera Co., Ltd., Tokyo, Japan), respectively. Chlorophyll fluorescence $(\mathrm{Fv} / \mathrm{Fm})$ and the relative chlorophyll values were measured using 3 and 8 plants $(n=3$ and $n=8$ ) in each replication at 32 days after transplanting, respectively. 


\subsection{Measurement of Leaf Gas Exchange Parameters}

A portable photosynthesis system LI-6400 (IRGA, Licor. Inc. Nebraska, NE, USA) was used to determine the transpiration rate $\left(\mathrm{T}_{\mathrm{r}}\right)$, net photosynthetic rate $\left(\mathrm{P}_{\mathrm{n}}\right)$, intercellular $\mathrm{CO}_{2}$ concentration $\left(\mathrm{C}_{\mathrm{i}}\right)$, and stomatal conductance $\left(\mathrm{g}_{\mathrm{s}}\right)$ at 31 days after transplanting on the third leaf from the plant apex. The airflow rate, block temperature, and $\mathrm{CO}_{2}$ concentration were set at $500 \mathrm{~cm}^{3} \cdot \mathrm{s}^{-1}, 25^{\circ} \mathrm{C}$, and $400 \mu \mathrm{mol} \cdot \mathrm{mol}^{-1}$, respectively. These parameters were measured on five plants per each replication and for each IAA treatment. Plants used for measuring chlorophyll fluorescence (Fv/Fm), relative chlorophyll values, and leaf gas exchange parameters belonged to the list of eight plants that were used to measure plant growth parameters. All samples were selected by the randomization method.

\subsection{Analysis of Acacetin, Tilianin, and Rosmarinic Acid (RA) Concentrations and Contents}

The acacetin, tilianin, and RA of $A$. rugosa were analyzed according to the literatures $[5,18]$ with modifications. Roots, stems, leaves, and flowers of three plant samples per replication from each IAA treatment group were placed in liquid nitrogen immediately after harvest and stored at $-70^{\circ} \mathrm{C}$ in a deep freezer and then put into a dry freezer. Materials for analysis were obtained from three randomly selected plants $(n=3)$. After the dried A. rugosa samples of root, stem, leaf, and flower were ground to a fine powder and filtered by a sieve, a $100 \mathrm{mg}$ sample was accurately weighed and placed in a $2.0 \mathrm{~mL}$ tube, to which $80 \%(v / v)$ methanol $(1.5 \mathrm{~mL})$ was added and blended by a vortex, with sonication being conducted for $60 \mathrm{~min}$. The mixed solution was centrifuged for $10 \mathrm{~min}$ at $13,000 \times \mathrm{g}$ by a microcentrifuge (R17 Plus, Hanil Scientific Co., Ltd., Gimpo, Korea). Then the supernatant was filtered by a $0.45 \mu \mathrm{m}$ filter for high-performance liquid chromatography (HPLC) analysis. The HPLC conditions for $A$. rugosa were C18 column ( $250 \mathrm{~mm} \times 4.6 \mathrm{~mm}, 5 \mu \mathrm{m}$; RS tech, Daejeon, Korea); flow rate, one mL/min; temperature, $30^{\circ} \mathrm{C}$; run time, $60 \mathrm{~min}$; detector wavelength, $275 \mathrm{~nm}$; mobile phase, $100 \%$ methanol and $0.20 \%(v / v)$ acetic acid; and injection volume, $20 \mu \mathrm{L}$. The tilianin, RA, and acacetin analytical standards were purchased from (Sigma-Aldrich, Co., Ltd., Seoul, Korea). HPLC was performed by reversed-phase HPLC-ultraviolet analysis (1260 Infinity, Agilent Technologies, Santa Clara, CA, USA) to determine the acacetin, RA, and tilianin concentrations, which were expressed as milligrams of acacetin, tilianin, and RA concentrations equivalent per gram of each plant organ dry weight $\left(\mathrm{mg} \cdot \mathrm{g}^{-1}\right.$ DW) [17]. Whole plant concentration ( $\mathrm{mg}^{-1}$ plant DW) means the total of tilianin, acacetin, and RA concentrations of all plant organs. The RA, acacetin, and tilianin contents in stems, roots, leaves, and flowers (mg/plant organs DW) mean the RA, acacetin, and tilianin concentrations in the plant organs (mg. ${ }^{-1} \mathrm{DW}$ ) multiplied by plant organs DW (g). The RA, acacetin, and tilianin contents in the whole plant (mg/plant DW) mean the RA, acacetin, and tilianin concentrations $\left(\mathrm{mg}^{-\mathrm{g}^{-1}}\right.$ plant DW) multiplied by whole plant DW $(\mathrm{g})$.

\subsection{Statistical Analysis}

The IAA experiment was repeated twice by a completely randomized design. Statistical analysis was performed by SPSS 20.0 software program (SPSS 20, SPSS Inc., Chicago, IL, USA). An analysis of variance (ANOVA) was conducted. The significant differences among the means of IAA treatments were determined by Tukey's multiple range test at 5\%. SigmaPlot 10 (Systat Software Inc., San Jose, CA, USA) was used to build the graphs.

\section{Results}

\subsection{Plant Growth Parameters}

At 32 days after transplanting, leaf length and width, the number of leaves, shoot and root fresh weights, and root dry weight differed significantly according to the IAA concentrations and from that of the control (Table 1). Of the four IAA treatments, $10^{-11} \mathrm{M}$ induced the maximum leaf length and width, which was significantly higher (1.05- and 1.13-times, respectively) than that of the control. In contrast, $10^{-11} \mathrm{M}$ IAA treatment showed the fewest leaves compared to the other IAA treatments 
and the control. The leaf area, stem and root lengths, and shoot dry weight did not differ significantly with IAA treatments and the control. The $10^{-5} \mathrm{M}$ IAA treatment tended to inhibit root fresh weight, shoot and root dry weights, although no significant difference was observed compared with the control. Plants under $10^{-11}$ M IAA treatments did not exhibit improved shoot and root fresh weights compared with the control, whereas $10^{-7}$ and $10^{-9}$ M IAA treatments improved shoot and root fresh weights compared with the control. There was no significant difference in some growth parameters between IAA treatments and the control.

\subsection{Relative Chlorophyll Value, Chlorophyll Fluorescence (Fv/Fm), and Leaf Gas Exchange Parameters}

There was no significant difference in relative chlorophyll and Fv/Fm ratio values between IAA treatments and the control (Figure 2A,B). The net photosynthesis rate of $A$. rugosa treated with $10^{-7}$ and $10^{-9}$ M IAA concentration was significantly higher than that of the control and other IAA treatments, and the $10^{-5} \mathrm{M}$ IAA concentration treatment showed the lowest net photosynthesis rate among all treatments (Figure $3 \mathrm{~A}$ ). This trend was observed in the stomatal conductance $\left(\mathrm{g}_{\mathrm{s}}\right)$ (Figure 2B), intercellular $\mathrm{CO}_{2}$ concentration $\left(\mathrm{C}_{\mathrm{i}}\right)$ (Figure $\left.3 \mathrm{C}\right)$, and transpiration rate $\left(\mathrm{T}_{\mathrm{r}}\right)$ (Figure $3 \mathrm{D}$ ), which were significantly increased under $10^{-7}$ and $10^{-9}$ M IAA treatments compared with the other IAA treatments and the control.
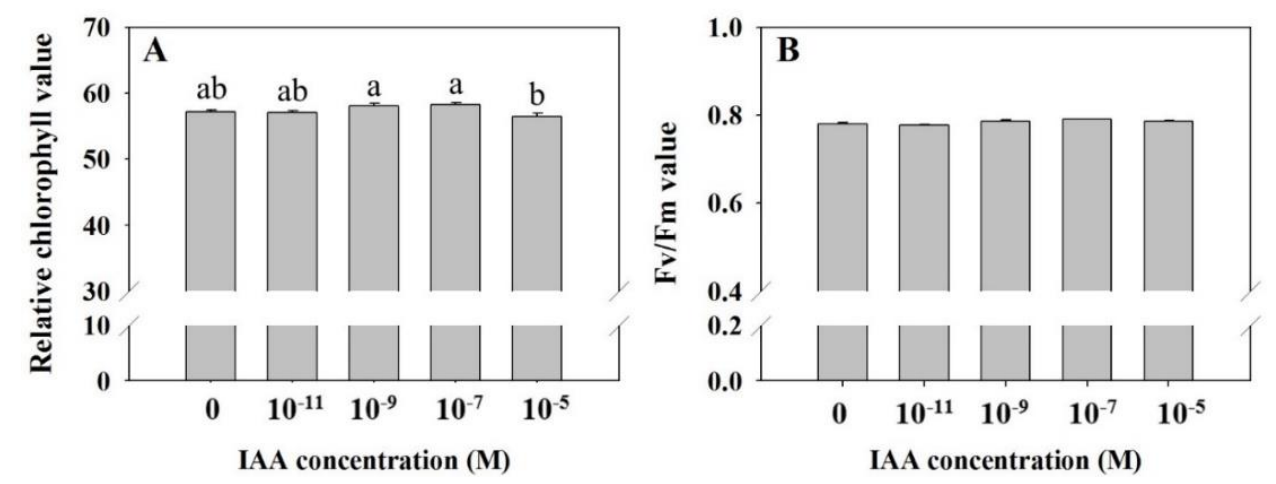

Figure 2. Relative chlorophyll value (A) and $\mathrm{Fv} / \mathrm{Fm}$ value ratio (B) of $A$. rugosa subjected to the control (without IAA) and four IAA treatments. Different letters $(\mathrm{a}-\mathrm{b})$ indicate significant differences among treatments at $p \leq 0.05(n=8$ and $n=3)$. 
Table 1. Plant growth parameters of Agastache rugosa subjected to the control (without IAA) and four IAA treatments.

\begin{tabular}{|c|c|c|c|c|c|c|c|c|c|c|}
\hline \multirow{2}{*}{$\begin{array}{l}\text { IAA Concentration }{ }^{\mathrm{w}} \\
\text { (M) }\end{array}$} & \multirow{2}{*}{$\begin{array}{l}\text { Leaf Length } \\
(\mathrm{cm})\end{array}$} & \multirow{2}{*}{$\begin{array}{l}\text { Leaf Width } \\
\qquad(\mathrm{cm})\end{array}$} & \multirow{2}{*}{$\begin{array}{l}\text { Number of } \\
\text { Leaves }\end{array}$} & \multirow{2}{*}{$\begin{array}{l}\text { Leaf Area } \\
\qquad\left(\mathrm{cm}^{2}\right)\end{array}$} & \multirow{2}{*}{$\begin{array}{c}\text { Stem } \\
\text { Length }(\mathrm{cm})\end{array}$} & \multirow{2}{*}{$\begin{array}{l}\text { Root Length } \\
\text { (cm) }\end{array}$} & \multicolumn{2}{|c|}{ Fresh Weight (g/plant) } & \multicolumn{2}{|c|}{ Dry Weight (g/plant) } \\
\hline & & & & & & & Shoot & Root & Shoot & Root \\
\hline Control & $9.09 \mathrm{bc}$ & $7.54 \mathrm{c}$ & $78.50 \mathrm{ab}$ & 860.25 & 41.86 & 54.85 & $25.56 \mathrm{bc}$ & $15.69 \mathrm{ab}$ & 3.12 & $0.80 \mathrm{ab}$ \\
\hline $10^{-11}$ & $9.51 \mathrm{a}$ & $8.52 a$ & $76.50 \mathrm{~b}$ & 845.56 & 41.19 & 50.74 & $25.74 \mathrm{abc}$ & $14.98 \mathrm{ab}$ & 3.01 & $0.78 \mathrm{ab}$ \\
\hline $10^{-9}$ & $9.45 \mathrm{ab}$ & $8.10 \mathrm{~b}$ & $84.87 a$ & 893.53 & 40.46 & 55.34 & $28.65 a$ & $16.69 a$ & 3.14 & $0.81 \mathrm{a}$ \\
\hline $10^{-7}$ & $9.06 \mathrm{bc}$ & $8.06 \mathrm{~b}$ & $85.50 \mathrm{a}$ & 925.99 & 41.61 & 57.49 & $28.38 \mathrm{ab}$ & $16.76 \mathrm{a}$ & 3.15 & $0.81 \mathrm{a}$ \\
\hline $10^{-5}$ & $8.74 \mathrm{c}$ & $7.91 \mathrm{~b}$ & $78.25 \mathrm{ab}$ & 858.28 & 40.97 & 50.91 & $25.09 c$ & $14.70 \mathrm{~b}$ & 2.95 & $0.75 b$ \\
\hline Significance $\mathrm{z}$ & $* * *$ & $* * *$ & ** & NS & NS & NS & ** & ** & NS & ** \\
\hline $\mathrm{L}^{\mathrm{y}}$ & $*$ & $* * *$ & NS & NS & NS & NS & NS & NS & NS & NS \\
\hline $\mathrm{Q}^{\mathrm{x}}$ & $* * *$ & $* * *$ & NS & NS & NS & NS & NS & NS & NS & NS \\
\hline
\end{tabular}

${ }^{\mathrm{w}}$ IAA concentration treatments. Data are the mean of eight separate plants $(n=8)$. Different letters $(\mathrm{a}-\mathrm{c})$ indicate significant differences among treatments at the level of $5 \%$ according to Tukey's test. NS: Not significant $(p>0.05),{ }^{\mathrm{z}}$ significant at ${ }^{*} p \leq 0.05,{ }^{* *} p \leq 0.01$, and ${ }^{* * *} p \leq 0.001$. ${ }^{\text {y }}$ L: linear, ${ }^{\times}$Q: quadratic in regression analysis. 

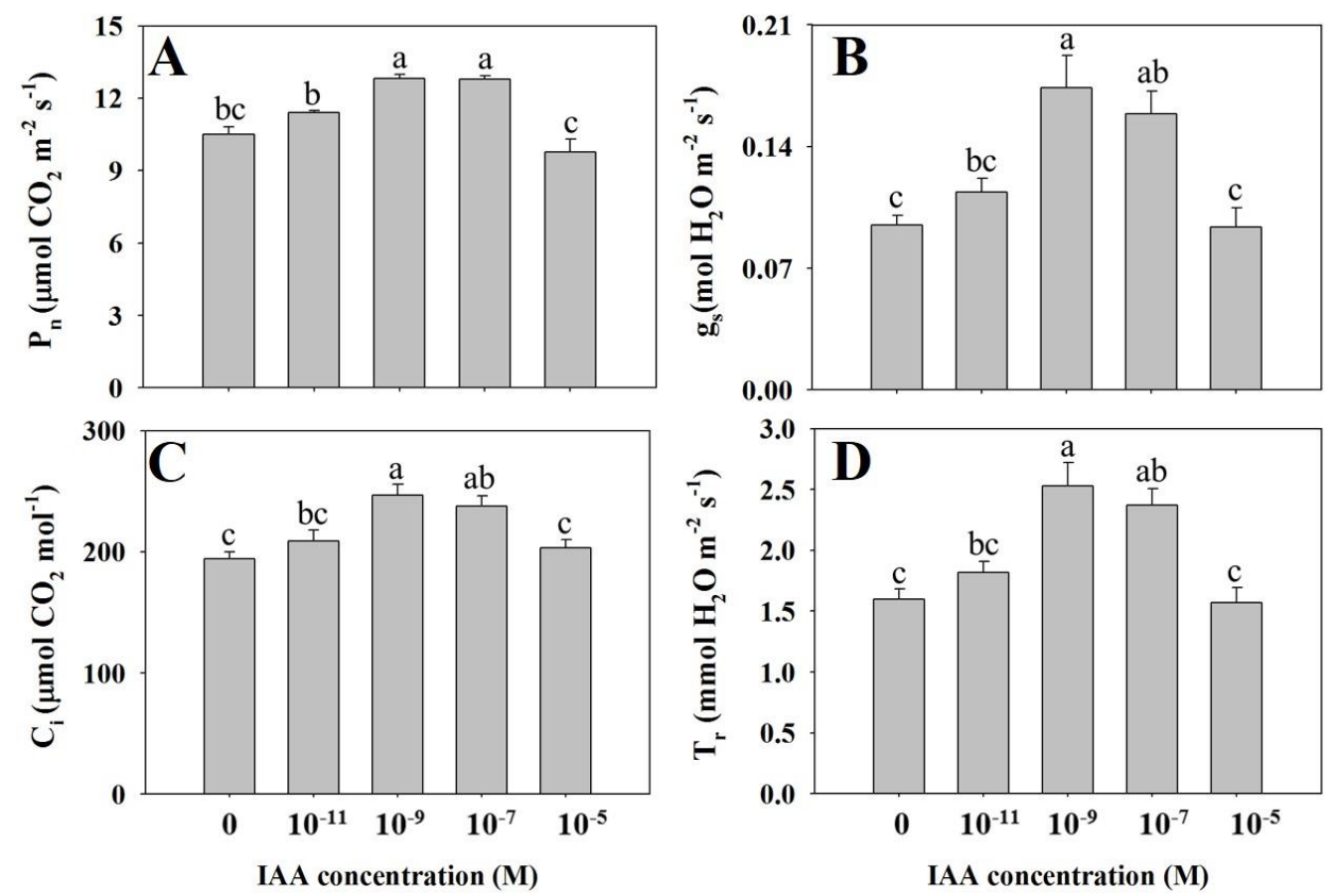

Figure 3. Net photosynthetic rate $\left(\mathrm{P}_{\mathrm{n}}\right)(\mathrm{A})$, stomatal conductance $\left(\mathrm{g}_{\mathrm{s}}\right)(\mathbf{B})$, intercellular $\mathrm{CO}_{2}$ concentration $\left(\mathrm{C}_{\mathrm{i}}\right)(\mathrm{C})$, and transpiration rate $\left(\mathrm{T}_{\mathrm{r}}\right)(\mathrm{D})$ of $A$. rugosa subjected to the control (without IAA) and four IAA treatments. Different letters $(\mathrm{a}-\mathrm{c})$ indicate significant differences among treatments at $p \leq 0.05(n=5)$.

\subsection{Acacetin, Rosmarinic Acid (RA), and Tilianin Concentrations and Contents}

The tilianin, RA, and acacetin concentrations were separately analyzed in the leaves, roots, flowers, and stems of the A. rugosa plants treated with different IAA concentrations and they showed significant differences (Table 2). Among the IAA treatments, RA concentrations in leaves at $10^{-9} \mathrm{M}$ and in stem at $10^{-7} \mathrm{M}$ were the highest amount compared with other treatments, which were significantly higher (1.7 and 1.4 times, respectively) than that of the control. However, the RA concentration in flowers was lower under $10^{-7}$ and $10^{-9} \mathrm{M}$ IAA concentrations compared with the control and other IAA treatments. Furthermore, the $10^{-5}$ M IAA treatment showed the highest RA concentration in roots, which was 1.6 times higher than the control (Table 2). Table 3 shows that the RA content in leaves and stems exposed to $10^{-9}$ and $10^{-7}$ M IAA was significantly increased by 1.7- and 1.4-times, respectively, compared to that of the control. There was no significant difference in RA contents in the flowers at $p>0.05$ ( $p=0.077)$ between four IAA treatments and the control; however, RA contents in roots was the highest amount at the treatment of $10^{-5} \mathrm{M}$ IAA compared to the control and other IAA treatments (Table 3).

Tilianin concentration was significantly increased up to 1.6-time (in leaves) and 1.8-time (in stems) at $10^{-11}$ M IAA, respectively, compared with the control. Most notably, all IAA treatments had a significantly higher tilianin concentration in leaves and stems than that of the control. Tilianin concentration in flowers exhibited a similar trend: Plants exposed to IAA treatments exhibited significantly increased tilianin concentrations compared to those of the control. The roots under $10^{-5} \mathrm{M}$ IAA treatment reached their highest levels of tilianin concentration, which was significantly (2.2 times) higher than that of the control (Table 2). Table 3 shows that tilianin content in leaves, stems, and roots exhibited a tendency similar to the results reported for tilianin concentration. Tilianin content in leaves and stems was the highest at $10^{-11} \mathrm{M}$ IAA, and in roots at $10^{-5}$ M IAA compared to the control and other treatments. Especially, the flower's tilianin contents in all IAA treatments were higher than the control. 
Table 2. Rosmarinic acid (RA), tilianin, and acacetin concentrations ( $\mathrm{mg}^{-1}{ }^{-1} \mathrm{DW}$ ) in flowers, leaves, roots, and stems of $A$. rugosa subjected to the control (without IAA) and four IAA treatments.

\begin{tabular}{|c|c|c|c|c|c|c|c|c|c|c|c|c|}
\hline \multirow{2}{*}{$\begin{array}{l}\text { IAA Concentration }{ }^{w} \\
\text { (M) }\end{array}$} & \multicolumn{4}{|c|}{$\begin{array}{c}\text { RA Concentration in Plant Organs } \\
\left(\mathrm{mg} \cdot \mathrm{g}^{-1} \mathrm{DW}\right)\end{array}$} & \multicolumn{4}{|c|}{$\begin{array}{c}\text { Tilianin Concentration in Plant Organs } \\
\left(\mathrm{mg} \cdot \mathrm{g}^{-1} \mathrm{DW}\right)\end{array}$} & \multicolumn{4}{|c|}{$\begin{array}{c}\text { Acacetin Concentration in Plant Organs } \\
\left(\mathrm{mg} \cdot \mathrm{g}^{-1} \text { DW }\right)\end{array}$} \\
\hline & Leaves & Flowers & Stems & Roots & Leaves & Flowers & Stems & Roots & Leaves & Flowers & Stems & Roots \\
\hline Control & $3.718 \mathrm{~d}$ & $6.163 a$ & $6.379 b c$ & $19.153 b$ & $1.480 \mathrm{c}$ & $2.919 b$ & $0.931 \mathrm{~d}$ & $0.033 c$ & ND & $0.064 \mathrm{~b}$ & ND & ND \\
\hline $10^{-11}$ & $4.604 c$ & $5.304 \mathrm{ab}$ & $5.495 \mathrm{~d}$ & $10.348 \mathrm{c}$ & $2.311 \mathrm{a}$ & $5.781 \mathrm{a}$ & $1.715 \mathrm{a}$ & $0.034 \mathrm{c}$ & ND & $0.059 \mathrm{~b}$ & ND & ND \\
\hline $10^{-9}$ & $6.392 a$ & $5.076 \mathrm{~b}$ & $6.809 \mathrm{~b}$ & $24.307 \mathrm{ab}$ & $1.908 \mathrm{~b}$ & $5.011 \mathrm{a}$ & $1.150 \mathrm{c}$ & $0.038 \mathrm{c}$ & ND & $0.033 c$ & ND & ND \\
\hline $10^{-7}$ & $5.919 \mathrm{~b}$ & $4.905 \mathrm{~b}$ & $9.075 \mathrm{a}$ & $23.218 b$ & $1.706 \mathrm{~b}$ & $4.817 \mathrm{a}$ & $1.209 \mathrm{bc}$ & $0.055 b$ & ND & $0.110 \mathrm{a}$ & ND & ND \\
\hline $10^{-5}$ & $6.041 \mathrm{~b}$ & $5.606 \mathrm{ab}$ & $6.068 \mathrm{~cd}$ & $29.925 a$ & $1.744 \mathrm{~b}$ & $4.399 \mathrm{a}$ & $1.345 \mathrm{~b}$ & $0.074 a$ & ND & $0.104 a$ & ND & ND \\
\hline Significance $^{\mathrm{z}}$ & $* * *$ & $* *$ & $* * *$ & ** & $* * *$ & $* *$ & $* * *$ & $* * *$ & ND & $* * *$ & ND & ND \\
\hline$Q^{x}$ & $* * *$ & $* *$ & NS & $* * *$ & $* * *$ & $* * *$ & $* *$ & $* * *$ & ND & $*$ & ND & ND \\
\hline
\end{tabular}

Wifferent letters (a-d) indicate significant differences among treatments at the level of $5 \%$ according to Tukey's test. NS: Not significant $(p>0.05),{ }^{\mathrm{z}}$ significant at ${ }^{*} p \leq 0.05,{ }^{* *} p \leq 0.01$, and ${ }^{* * *} p \leq 0.001 .{ }^{\mathrm{y}}$ L: linear, ${ }^{\mathrm{x}} \mathrm{Q}$ : quadratic in regression analysis. ND: not detected; DW: dry weight.

Table 3. Rosmarinic acid (RA), tilianin, and acacetin contents (mg/plant organs DW) in stems, leaves, roots, and flowers of $A$. rugosa subjected to the control (without IAA) and four IAA treatments.

\begin{tabular}{|c|c|c|c|c|c|c|c|c|c|c|c|c|}
\hline \multirow{2}{*}{$\begin{array}{l}\text { IAA Concentration }{ }^{w} \\
\text { (M) }\end{array}$} & \multicolumn{4}{|c|}{$\begin{array}{l}\text { RA Content in Plant Organs } \\
(\mathrm{mg} / \text { plant organs DW) }\end{array}$} & \multicolumn{4}{|c|}{$\begin{array}{l}\text { Tilianin Content in Plant Organs } \\
\text { (mg/plant organs DW) }\end{array}$} & \multicolumn{4}{|c|}{$\begin{array}{l}\text { Acacetin Content in Plant Organs } \\
(\mathrm{mg} / \text { plant organs DW) }\end{array}$} \\
\hline & Leaves & Flowers & Stems & Roots & Leaves & Flowers & Stems & Roots & Leaves & Flowers & Stems & Roots \\
\hline Control & $7.325 d$ & $1.309 a$ & $5.763 c$ & $15.429 b$ & $2.915 c$ & $0.601 \mathrm{~b}$ & $0.841 \mathrm{c}$ & $0.027 \mathrm{c}$ & ND & $0.014 \mathrm{~b}$ & ND & ND \\
\hline $10^{-11}$ & $8.670 c$ & $1.061 \mathrm{~b}$ & $4.962 \mathrm{~d}$ & $8.139 c$ & $4.353 a$ & $1.156 a$ & $1.549 a$ & $0.026 c$ & ND & $0.012 b$ & ND & ND \\
\hline $10^{-9}$ & $12.231 \mathrm{a}$ & $1.083 \mathrm{ab}$ & $6.582 \mathrm{~b}$ & $20.101 \mathrm{ab}$ & $3.651 b$ & $1.068 \mathrm{a}$ & $1.112 \mathrm{~b}$ & $0.031 \mathrm{c}$ & ND & $0.007 \mathrm{c}$ & ND & ND \\
\hline $10^{-7}$ & $11.719 b$ & $1.030 \mathrm{~b}$ & $8.228 \mathrm{a}$ & $19.119 \mathrm{ab}$ & $3.378 b$ & $1.011 \mathrm{a}$ & $1.096 \mathrm{~b}$ & $0.045 b$ & ND & $0.023 a$ & ND & ND \\
\hline $10^{-5}$ & $11.559 \mathrm{~b}$ & $1.156 \mathrm{ab}$ & $5.099 \mathrm{~d}$ & $22.745 a$ & $3.337 \mathrm{bc}$ & $0.909 \mathrm{ab}$ & $1.131 \mathrm{~b}$ & $0.056 \mathrm{a}$ & ND & $0.021 \mathrm{a}$ & ND & ND \\
\hline Significance $^{\mathrm{z}}$ & $* * *$ & NS & $* * *$ & $* * *$ & $* * *$ & $* *$ & $* * *$ & $* * *$ & ND & $* * *$ & ND & ND \\
\hline$L^{y}$ & NS & $* *$ & NS & NS & $* * *$ & $* * *$ & $* * *$ & NS & ND & NS & ND & ND \\
\hline$Q^{x}$ & $* * *$ & $* *$ & NS & $* * *$ & $* * *$ & $* * *$ & $* * *$ & $* * *$ & ND & * & ND & ND \\
\hline
\end{tabular}

w IAA concentration treatments. Data are the mean of three separate plants $(n=3)$. Different letters $(\mathrm{a}-\mathrm{d})$ indicate significant differences among treatments at the level of $5 \%$ according to Tukey's test. NS: Not significant $(p>0.05),{ }^{\mathrm{z}}$ significant at ${ }^{*} p \leq 0.05,{ }^{* *} p \leq 0.01$, and ${ }^{* * *} p \leq 0.001 .{ }^{\mathrm{y}}$ L: linear, ${ }^{\mathrm{x}}$ Q: quadratic in regression analysis. ND: not detected; DW: dry weight. 
Acacetin concentration in flowers was significantly higher in $10^{-5}$ and $10^{-7} \mathrm{M}$ IAA treatments compared with the control and other IAA treatments (Table 2). The acacetin concentration in stems was detected a minimal amount in $10^{-5}, 10^{-7}$, and $10^{-9}$ M IAA treatments (data not shown). The acacetin concentration was undetectable in roots and leaves. The acacetin content in flowers showed a similar trend to the results reported for acacetin concentration, which was significantly higher under $10^{-5}$ and $10^{-7}$ M IAA treatments compared with the control and other IAA treatments (Table 3 ). In addition, the RA concentration was the highest in the roots and the tilianin concentration was the highest in the flowers. The RA concentration was greater than the acacetin and tilianin concentrations in A. rugosa (Table 2 and Figure 4).
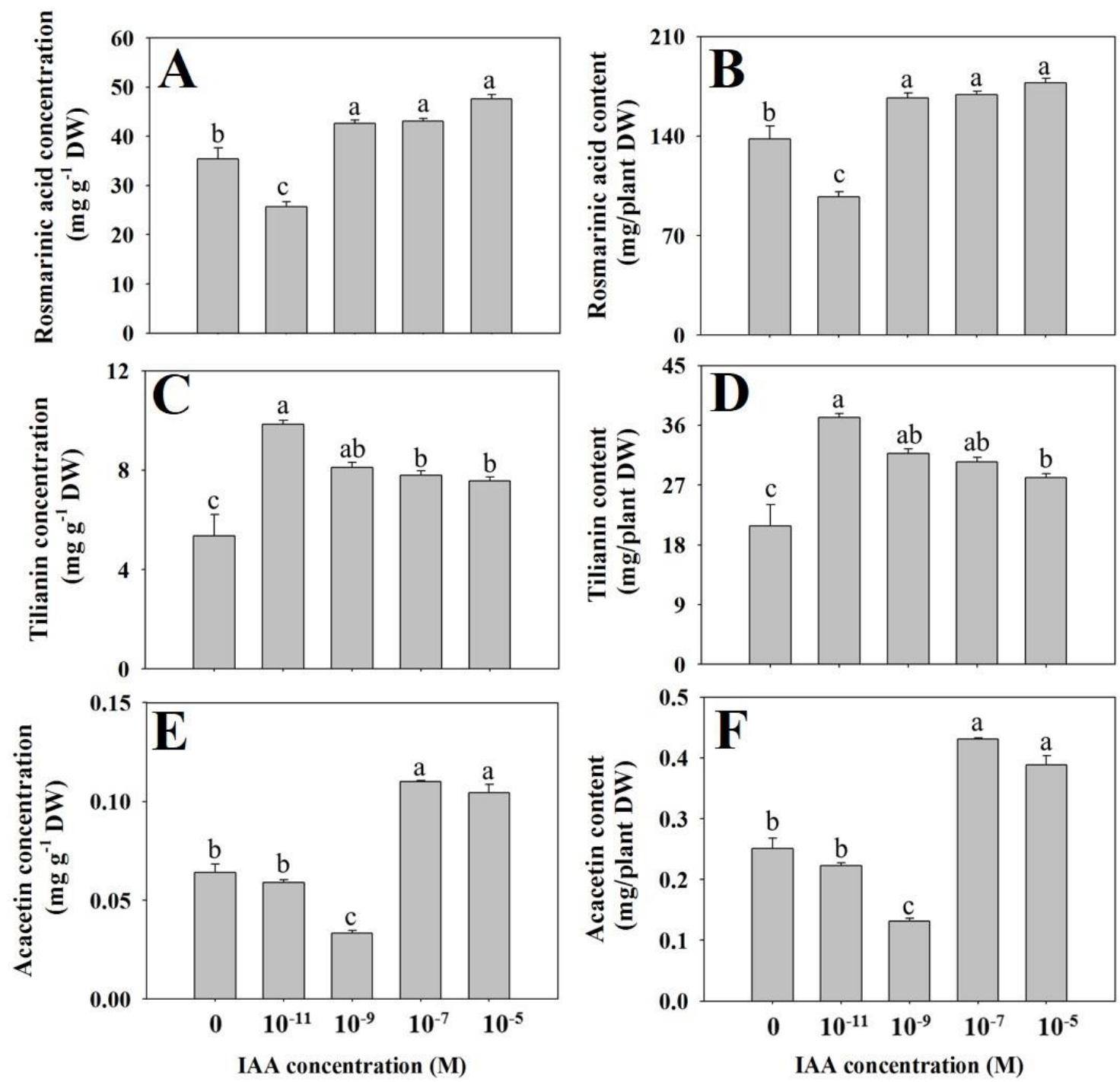

Figure 4. Rosmarinic acid (A,B), tilianin (C,D), and acacetin (E,F) concentrations and contents in the whole plant of $A$. rugosa subjected to the control (without IAA) and four IAA treatments. Different letters $(\mathrm{a}-\mathrm{c})$ indicate significant differences among treatments at $p \leq 0.05(n=3)$.

Three of the four IAA treatments, except $10^{-11} \mathrm{M}$, significantly increased the RA concentration per plant compared with that of the control. The RA concentration per plant was the significantly lowest under $10^{-11}$ M IAA treatment (Figure 4A). The RA content per plant also showed a similar trend to RA concentration (Figure 4B). All four IAA treatments significantly increased the tilianin concentration of A. rugosa compared with that of the control. Especially, $10^{-11} \mathrm{M}$ maximized the tilianin concentration per plant, which was significantly (1.8 times) higher than that in the control (Figure 4C). The tilianin 
content per plant in response to IAA concentrations followed the same trend as that for the tilianin concentration (Figure 4D). The $10^{-5}$ and $10^{-7}$ M IAA treatments induced significantly higher acacetin concentration (1.6- and 1.7-time, respectively) than that of the control (Figure 4E). A similar trend was observed for acacetin content (Figure 4F).

\section{Discussion}

\subsection{Plant Growth Parameters}

To understand the suitability of IAA concentration for A. rugosa growth, we investigated the growth parameters of plants grown under IAA dissolved in Hoagland nutrient solution compared to the control (without IAA). There was no significant difference in some growth parameters between IAA treatments and the control. However, shoot fresh weight under $10^{-9} \mathrm{M}$ IAA treatment was significantly higher than that of the control. Treatments at $10^{-7}$ and $10^{-9} \mathrm{M}$ IAA tended to increase the leaf number and leaf area compared with other IAA treatments and the control. IAA's primary efficiency was to stimulate the development of stems and roots, lateral root production, and root elongation by extending the new cells in the meristem [26]. The growth-stimulating phytohormone auxin is known to cause root growth by increasing cell division and cell extension [27]. The lateral root density per plant of Trichoderma virens was doubled under IAA treatment compared with that of the control (without IAA) [28].

In contrast, the IAA concentration at $10 \mu \mathrm{M}$ reduced shoot and root growth of chickpea after 10 days of treatment [29]. The influence of IAA has been determined based on the concentration, with low and high IAA concentrations increasing and restricting plant growth, respectively [20,29]. For example, root and shoot growth of sunflower plants grown under a hydroponic system was effectively enhanced under $10^{-10} \mathrm{M}$ IAA concentration [30]. The number of cells in Chlorella vulgaris was the highest under an IAA concentration of $0.1 \mu \mathrm{M}$ [20]. A higher concentration of IAA at $10.0 \mu \mathrm{M}$ restricted the seedling's growth of chickpea when compared with lower IAA concentration at 0.5 and 1.0 $\mu$ M IAA [29]. Shoot and root growth of sunflower were effectively increased in $10^{-10} \mathrm{M}$ IAA concentration [30]. The IAA concentration in nutrient solution at $10^{-6} \mathrm{M}$ reduced $\mathrm{K}$ and $\mathrm{Mg}$ contents and increased $\mathrm{Ca}$ in leaves, but increased $\mathrm{N}, \mathrm{P}, \mathrm{K} \mathrm{Ca}, \mathrm{Fe}, \mathrm{Cu}, \mathrm{Zn}$, and $\mathrm{Mn}$ contents in the roots of pepper plants, probably due to the increase of plasmalemma $\mathrm{H}^{+}$pump activity in the cells [31]. Plant height, the number of leaves, leaf dry weight, root and stem dry weights, and leaf water content were increased under $10^{-6} \mathrm{M}$ IAA concentration compared with those of the control (without IAA). The same patterns were observed for l-tryptophan and indole treatments [31]. This is in agreement with our results that the number of leaves, leaf area, shoot fresh and dry weights of $A$. rugosa were increased at medium IAA concentration $\left(10^{-7}\right.$ and $\left.10^{-9} \mathrm{M}\right)$, and leaf length and width were increased at low IAA concentration $\left(10^{-11} \mathrm{M}\right)$ compared to the control and other IAA treatments; however, high IAA concentration $\left(10^{-5} \mathrm{M}\right)$ tended to reduce plant growth, probably ion imbalance occurred at high IAA concentration. Use of $10^{-10} \mathrm{M}$ IAA decreased the toxic influences of $\mathrm{Pb}$ and $\mathrm{Zn}$ on the root and shoot growth [30]. Therefore, the optimum IAA concentration for growth depends on the kind of plants and cultivation methods.

\subsection{Chlorophyll Fluorescence $\left(F_{v} / F_{m}\right)$, Relative Chlorophyll Value, and Leaf Gas Exchange Parameters}

This study has demonstrated that the relative chlorophyll values at $10^{-7}$ and $10^{-9}$ M IAA treatments were higher than those at the other IAA treatments and the control, but not significantly. There was no significant difference in $\mathrm{Fv} / \mathrm{Fm}$ ratio between IAA treatments and the control. However, plants cultivated in-vitro method exhibited stimulated levels of chlorophyll synthesis at high IAA concentrations. For example, the chlorophyll synthesis in Scenedesmus quadricauda and Chlorella pyrenoidosa was strongly enhanced at high IAA concentrations ( 40 and $60 \mathrm{mg} \cdot \mathrm{L}^{-1}$, respectively) [32]. In contrast, IAA concentration at $0.1 \mu \mathrm{M}$ exerted a positive effect on chlorophyll in chlorella vulgaris after $48 \mathrm{~h}$ of cultivation [20], whereas $1 \mu \mathrm{M}$ IAA treatment did not influence chlorophyll synthesis in Arabidopsis [33]. 
All leaf gas exchange parameters were higher at $10^{-7}$ and $10^{-9}$ M IAA treatments compared with the control and other IAA treatments. The optimal IAA positively affected plant growth by extending leaves and raising the photosynthetic rate of plants, and it also induced the translocation of carbohydrates in the synthesis process. [34]. Similarly, auxin concentration at $100 \mathrm{mg} \cdot \mathrm{L}^{-1}$ stimulated and thus increased the photosynthetic rate and stomatal conductance in mustard [34]. Auxins (IAA, IBA, and NAA) had a positive influence on photosynthesis [32], probably because auxin enhances nutrient uptake such as $\mathrm{N}, \mathrm{P}$, and $\mathrm{K}$ [31]. The IAA solution augments the rate of $\mathrm{CO}_{2}$ assimilation and photosynthesis rate in leaves [35]. In this study, the optimal IAA concentrations at $10^{-7}$ and $10^{-9} \mathrm{M}$ increased leaf gas exchange parameters.

\subsection{Rosmarinic Acid (RA), Tilianin, and Acacetin Concentrations and Contents}

The RA concentration per plant was significantly higher under almost all IAA treatments except $10^{-11}$ M IAA treatment compared with that of the control (Figure $4 \mathrm{~A}$ ). In addition, all IAA treatments significantly increased the concentration of tilianin in A. rugosa compared to the control, and $10^{-11} \mathrm{M}$ IAA treatment showed the highest value of tilianin compared to the control and other IAA treatments (Figure $4 \mathrm{C}$ ). The $10^{-5}$ and $10^{-7}$ M IAA treatments showed significantly higher acacetin concentration than the control and other IAA treatments. A similar trend was observed for RA, tilianin, and acacetin contents in A. rugosa (Figure 4B,D,F). Because auxins (IAA and IBA) increased the activities of CAT, SOD, and APX [20], the increase in SOD activity can be used to adjust $\mathrm{H}_{2} \mathrm{O}_{2}$ production [36]. Auxin enhanced antioxidant activity to control reactive oxygen species levels, which may correlate to the activity of embryo/organogenesis [21]. IAA enhances the antioxidant enzyme activities such as SOD, CAT, and peroxidases in Helianthus annuus L [37]. Glutathione and ascorbate in Chlorella vulgaris were increased under the IAA treatment compared with the control (without IAA) [20].

The contents of total phenol and flavonoid in the white mulberry tree were increased under the different concentrations of auxins such as IBA, IAA, and NAA [38]. The phenolic compound and flavonoid in gherkin pickles (Cucumis anguria L.) were improved by using IBA [39]. Protein and rutin contents in the white mulberry tree were increased by raising the IAA concentration [22]. Auxin increased the production of secondary metabolites and antioxidant activities in Aloe arborescens Mill [10]. In addition, IAA stress may lead to ion imbalance [31], which increased antioxidant enzymes and bioactive compounds in plants [25,40]. In this study, IAA treatments from $10^{-5}$ to $10^{-9} \mathrm{M}$ significantly increased RA, $10^{-9}$ to $10^{-11} \mathrm{M}$ significantly increased tilianin, and A. rugosa's acacetin concentration from $10^{-5}$ to $10^{-7} \mathrm{M}$ significantly increased compared to the control and other IAA treatments. Furthermore, the RA concentration was greater than tilianin and acacetin concentrations in the overall plant. Similar results were reported by Tuan et al. (2012) [5], who reported that RA concentration, which was higher than the acacetin and tilianin concentrations in A. rugosa. The same results were found by Lee et al. (2008) [4], who reported that RA was a main phenolic compound and concentrated in hairy roots of $A$. rugosa. In our study, acacetin and tilianin were mostly concentrated in flowers of $A$. rugosa while acacetin was undetectable in leaves, roots, and stems. Similar results were found by Tuan et al. (2012) [5] who reported that acacetin and tilianin were mainly extracted from the flowers of $A$. rugosa while acacetin was detected with very low amount in leaves $\left(0.06 \mu \mathrm{g} \cdot \mathrm{g}^{-1}\right)$ and undetectable in stems and roots.

These results showed that auxin dissolved in the nutrient solution could increase bioactive compounds in plants, but they mainly depend on plant species and auxin concentration levels. No report is presently available on the influence of IAA concentrations on the accumulation of bioactive compounds in A. rugosa. Our present results indicate that RA, tilianin, and acacetin concentrations were increased at $10^{-9} ; 10^{-7} ; 10^{-5}, 10^{-11} ; 10^{-9} ; 10^{-7} ; 10^{-5}$, and $10^{-7} ; 10^{-5}$ IAA treatments, respectively, compared with those of the control. However, the IAA concentration at $10^{-7} \mathrm{M}$ significantly increased RA, acacetin, and tilianin contents (Figure 4 B,D,F), net photosynthesis rate, and shoot fresh weight of A. rugosa compared with those of the control and other IAA treatments (Table 1 and Figure 3). IAA treatment at $10^{-11} \mathrm{M}$ reduced RA and acacetin content, and net photosynthesis rate, at $10^{-9} \mathrm{M}$ reduced 
acacetin content, and at $10^{-5} \mathrm{M}$ decreased tilianin content and shoot fresh weight compared with the other IAA treatments.

\section{Conclusions}

IAA dissolved in the nutrient solution improved several growth parameters and increased the production of bioactive compounds in A. rugosa while these effects were most pronounced at $10^{-7} \mathrm{M}$ IAA treatment. The results showed that IAA treatment at optimized concentration is most beneficial for enhancing plant growth and bioactive compound production in A. rugosa. Therefore, these results could be applied to optimize plant growth and bioactive compounds of $A$. rugosa in a plant factory. The IAA dissolved in the nutrient solution for herb plants in a plant factory can be used to produce ingredients for extractable nutraceutical in the drug industry and thereby enhance the healthy properties.

Author Contributions: V.P.L.: constructing the idea, setting up the experiments, data collection and analysis, writing-original manuscript, and writing-review and editing. M.H.L.: preparation for the manuscript, writing-review and editing. J.S.P.: project administration, supervision, constructing the idea, experimental design, data analysis, writing-original manuscript, and writing-review and editing. All authors have read and agreed to the published version of the manuscript.

Funding: This research was funded by Korea institute of machinery \& materials (KIMM), grant number NK225B.

Acknowledgments: This work was supported by Korea institute of machinery \& materials (KIMM) (NK225B).

Conflicts of Interest: The authors declare no conflicts of interest.

\section{References}

1. Yamani, H.; Mantri, N.; Morrison, P.D.; Pang, E. Analysis of the volatile organic compounds from leaves, flower spikes, and nectar of Australian grown Agastache Rugosa. BMC Complement. Altern. Med. 2014, 14, 1-6. [CrossRef]

2. Oliver, S.J. The role of traditional medicine practice in primary health care within Aboriginal Australia: A review of the literature. J. Ethnobiol. Ethnomed. 2013, 9, 46. [CrossRef]

3. Zielinska, S.; Matkowski, A. Phytochemistry and bioactivity of aromatic and medicinal plants from the genus Agastache (Lamiaceae). Phytochem. Rev. 2014, 13, 391-416. [CrossRef]

4. Lee, S.Y.; Xu, H.; Kim, Y.K.; Park, S.U. Rosmarinic acid production in hairy root cultures of Agastache rugosa Kuntze. World J. Microbiol. Biotechnol. 2008, 24, 969-972. [CrossRef]

5. Tuan, P.A.; Park, W.T.; Xu, H.; Park, N.I.; Park, S.U. Accumulation of tilianin and rosmarinic acid and expression of phenylpropanoid biosynthetic genes in Agastache Rugosa. J. Agric. Food Chem. 2012, 60, 5945-5951. [CrossRef] [PubMed]

6. Carmona-Castro, G.; Estrada-Soto, S.; Arellano-Garcia, J.; Arias-Duran, L.; Valencia-Diaz, S.; Perea-Arango, I. High accumulation of tilianin in in-vitro cultures of Agastache mexicana and its potential vasorelaxant action. Mol. Biol. Rep. 2019, 46, 1107-1115. [CrossRef] [PubMed]

7. Wei, J.F.; Cao, P.R.; Wang, J.M.; Kang, W.Y. Analysis of tilianin and acacetin in Agastache rugosa by high-performance liquid chromatography with ionic liquids-ultrasound based extraction. Chem. Cent. J. 2016, 10, 1-9. [CrossRef] [PubMed]

8. Guo, K.J.; Xu, S.F.; Yin, P.; Wang, W.; Song, X.Z.; Liu, F.H.; Xu, J.Q.; Zoccarato, I. Active components of common traditional Chinese medicine decoctions have antioxidant functions. J. Anim. Sci. 2011, 89, 3107-3115. [CrossRef]

9. Nadeem, M.; Imran, M.; Gondal, T.A.; Imran, A.; Shahbaz, M.; Amir, R.M.; Sajid, M.W.; Qaisrani, T.B.; Atif, M.; Hussain, G.; et al. Therapeutic potential of rosmarinic acid: A comprehensive review. Appl Sci. 2019, 9, 3139. [CrossRef]

10. Amoo, S.O.; Aremu, A.O.; Van Staden, J. In vitro plant regeneration, secondary metabolite production and antioxidant activity of micropropagated Aloe arborescens Mill. Plant Cell Tissue Organ Cult. 2012, 111, 345-358. [CrossRef]

11. Akanda, M.R.; Uddin, M.N.; Kim, I.S.; Ahn, D.; Tae, H.J.; Park, B.Y. The biological and pharmacological roles of polyphenol flavonoid tilianin. Eur. J. Pharm. 2019, 842, 291-297. [CrossRef] [PubMed] 
12. Semwal, R.B.; Semwal, D.K.; Combrinck, S.; Trill, J.; Gibbons, S.; Viljoen, A. Acacetin-A simple flavone exhibiting diverse pharmacological activities. Phytochem. Lett. 2019, 32, 56-65. [CrossRef]

13. Wink, M. Modes of action of herbal medicines and plant secondary metabolites. Medicines 2015, 2, 251-286. [CrossRef] [PubMed]

14. Kozai, T.; Niu, G.; Takagaki, M. Plant factory: An indoor vertical farming system for efficient quality food production. In Plant. Factory as a Resource-Efficient Closed Plant Production System, 2nd ed.; Kozai, T., Niu, G., Takagaki, M., Eds.; Academic Press: Cambridge, MA, USA, 2015; pp. 69-90.

15. Kim, Y.B.; Kim, J.K.; Uddin, M.R.; Xu, H.; Park, W.T.; Tuan, P.A.; Li, X.; Chung, E.; Lee, J.H.; Park, S.U. Metabolomics analysis and biosynthesis of rosmarinic acid in Agastache rugosa Kuntze treated with methyl jasmonate. PLoS ONE. 2013, 8, e64199. [CrossRef]

16. Kim, S.J.; Bok, K.J.; Lam, V.P.; Park, J.S. Response of nutrient solution and photosynthetic photon flux density for growth and accumulation of antioxidant in Agastache rugosa under hydroponic culture systems. Prot. Hortic. Plant. Fact. 2017, 26, 249-257. [CrossRef]

17. Lam, V.P.; Kim, S.J.; Bok, G.J.; Lee, J.W.; Park, J.S. The effects of root temperature on growth, physiology, and accumulation of bioactive compounds of Agastache Rugosa. Agriculture 2020, 10, 162. [CrossRef]

18. Lam, V.P.; Kim, S.J.; Park, J.S. Optimizing the electrical conductivity of a nutrient solution for plant growth and bioactive compounds of Agastache rugosa in a plant factory. Agronomy 2020, 10, 76. [CrossRef]

19. Bais, H.P.; Sudha, G.; George, J.; Ravishankar, G.A. Influence of exogenous hormones on growth and secondary metabolite production in hairy root cultures of Cichorium intybus L. cv. Lucknow Local. Vitr. Cell. Dev. Biol. Plant. 2001, 37, 293-299. [CrossRef]

20. Piotrowska-Niczyporuk, A.; Bajguz, A. The effect of natural and synthetic auxins on the growth, metabolite content and antioxidant response of green alga Chlorella vulgaris (Trebouxiophyceae). J. Plant. Growth Regul. 2014, 73, 57-66. [CrossRef]

21. Synkova, H.; Semoradova, S.; Schnablova, R.; Witters, E.; Husak, M.; Valcke, R. Cytokinin-induced activity of antioxidant enzymes in transgenic Pssu-ipt tobacco during plant ontogeny. Biol. Plant. 2006, 50, 31-41. [CrossRef]

22. Lee, Y.; Lee, D.E.; Lee, H.S.; Kim, S.K.; Lee, W.; Kim, S.H.; Kim, M.W. Influence of auxins, cytokinins, and nitrogen on production of rutin from callus and adventitious roots of the white mulberry tree (Morus alba L.). Plant. Cell Tissue Organ. Cult. 2011, 105, 9-19. [CrossRef]

23. Piotrowska-Niczyporuk, A.; Bajguz, A.; Kotowska, U.; Bralska, M.; Talarek-Karwel, M. Growth, metabolite profile, oxidative status, and phytohormone levels in the green alga Acutodesmus obliquus exposed to exogenous auxins and cytokinins. J. Plant. Growth Regul. 2018, 37, 1159-1174. [CrossRef]

24. Satdive, R.K.; Fulzele, D.P.; Eapen, S. Studies on production of ajmalicine in shake flasks by multiple shoot cultures of Cathar. Roseus. Biotechnol. Prog. 2003, 19, 1071-1075. [CrossRef] [PubMed]

25. Ding, X.; Jiang, Y.; Zhao, H.; Guo, D.; He, L.; Liu, F.; Zhou, Q.; Nandwani, D.; Hui, D.; Yu, J. Electrical conductivity of nutrient solution influenced photosynthesis, quality, and antioxidant enzyme activity of pakchoi (Brassica campestris L. ssp. Chinensis) in a hydroponic system. PLoS ONE 2018, 13, e0202090. [CrossRef] [PubMed]

26. Zhao, Y.D. Auxin biosynthesis and its role in plant development. Annu. Rev. Plant. Biol. 2010, 61, 49-64. [CrossRef]

27. Haber, A.H. Effects of indoleacetic acid on growth without mitosis \& on mitotic activity in absence of growth by expansion. Plant. Physiol. 1962, 37, 18-26.

28. Contreras-Cornejo, H.A.; Macías-Rodríguez, L.; Cortés-Penagos, C.; López-Bucio, J. Trichoderma virens, a plant beneficial fungus, enhances biomass production and promotes lateral root growth through an auxin-dependent mechanism in Arabidopsis. Plant. Physiol. 2009, 149, 1579-1592. [CrossRef]

29. Malik, D.K.; Sindhu, S.S. Production of indole acetic acid by Pseudomonas sp.: Effect of coinoculation with Mesorhizobium sp. Cicer on nodulation and plant growth of chickpea (Cicer arietinum). Physiol. Mol. Biol. Plants. 2011, 17, 25-32.

30. Fassler, E.; Evangelou, M.W.; Robinson, B.H.; Schulin, R. Effects of indole-3-acetic acid (IAA) on sunflower growth and heavy metal uptake in combination with ethylene diamine disuccinic acid (EDDS). Chemosphere 2010, 80, 901-907. [CrossRef] 
31. San-Francisco, S.; Houdusse, F.; Zamarreno, A.; Garnica, M.; Casanova, E.; Garcia-Mina, J. Effects of IAA and IAA precursors on the development, mineral nutrition, IAA content and free polyamine content of pepper plants cultivated in hydroponic conditions. Sci. Hortic. 2005, 106, 38-52. [CrossRef]

32. Liu, J.; Qiu, W.; Song, Y. Stimulatory effect of auxins on the growth and lipid productivity of Chlorella pyrenoidosa and Scenedesmus Quadricauda. Algal Res. 2016, 18, 273-280. [CrossRef]

33. Kobayashi, K.; Baba, S.; Obayashi, T.; Sato, M.; Toyooka, K.; Keränen, M.; Aro, E.M.; Fukaki, H.; Ohta, H.; Sugimoto, K.; et al. Regulation of root greening by light and auxin/cytokinin signaling in Arabidopsis. Plant Cell 2012, 24, 1081-1095. [CrossRef] [PubMed]

34. Khan, N.A.; Khan, M.; Ansari, H.R. Auxin and defoliation effects on photosynthesis and ethylene evolution in mustard. Sci. Hortic. 2002, 96, 43-51. [CrossRef]

35. Bidwell, R.G.S.; Turner, W.B. Effect of growth regulators on $\mathrm{CO}_{2}$ assimilation in leaves, and its correlation with the bud break response in photosynthesis. Plant. Physiol. 1966, 41, 267-270. [CrossRef]

36. Wang, Y.; Branicky, R.; Noë, A.; Hekimi, S. Superoxide dismutases: Dual roles in controlling ROS damage and regulating ROS signaling. J. Cell Biol. 2018, 217, 1915-1928. [CrossRef]

37. Kirecci, O.A. The effects of salt stress, SNP, ABA, IAA and GA applications on antioxidant enzyme activities in Helianthus Annuus L. Fresenius Environ. Bull. 2018, 27, 3783-3788.

38. Lee, E.J.; Kim, M.K.; Paek, K.Y. Auxin and cytokinin affect biomass and bioactive compound production from adventitious roots of Eleutherococcus Koreanum. Korean J. Hortic. Sci. Technol. 2010, 28, 678-684.

39. Thiruvengadam, M.; Chung, I.M. Phenolic compound production and biological activities from in vitro regenerated plants of gherkin (Cucumis anguria L.). Electron. J. Biotechnol. 2015, 18, 295-301. [CrossRef]

40. Galieni, A.; Di Mattia, C.; De Gregorio, M.; Speca, S.; Mastrocola, D.; Pisante, M.; Stagnari, F. Effects of nutrient deficiency and abiotic environmental stresses on yield, phenolic compounds and antiradical activity in lettuce (Lactuca sativa L.). Sci. Hortic. 2015, 187, 93-101. [CrossRef]

(C) 2020 by the authors. Licensee MDPI, Basel, Switzerland. This article is an open access article distributed under the terms and conditions of the Creative Commons Attribution (CC BY) license (http://creativecommons.org/licenses/by/4.0/). 